\title{
The Effects of Student Syndrome, Stress, and Slack on Information Systems Development Projects
}

\author{
D. C. Smith \\ University of Cape Town, Rondebosch, South Africa
}

derek.smith@uct.ac.za

\begin{abstract}
This research attempts to identify how Agile systems development methodologies like SCRUM are affected by three behavioural issues - student syndrome, team member stress and organisational slack. The student syndrome applies when humans start tasks as late as possible and waste safety margins thus increasing time pressure and stress levels. Stress can be both good and bad in a project situation. Stress levels that exceed an optimum level result in decreased performance and eventual burnout, whereas stress levels that were below a minimum level result in decreased performance. Organizational slack is a measure of "busyness" and is relates to staff being $100 \%$ scheduled. This is viewed as a short-term strategy which can negatively affect longer-term change and reinvention.

These three issues can affect project productivity and project outcomes. This research analyses how these three behavioral issues affect plan-based development approaches and agile approaches (specifically SCRUM) in terms of team productivity and project outcomes.

This paper describes these behavioural issues and how they could affect a typical systems development project. Four research questions were derived to be used in the next phase of the research. This next phase will identify a suitable student project which will be completed by an undergraduate student team using a traditional project approach at the same time as a post-graduate project team using SCRUM.
\end{abstract}

Keywords: Agile development, waterfall development, SCRUM, student syndrome, stress, slack

\section{Introduction}

The purpose of this research is to identify how Agile development methodologies like SCRUM are affected by the three behavioural aspects of student syndrome, levels of stress and the amount of organisational slack. The context is a systems development student team pro-

Material published as part of this publication, either on-line or in print, is copyrighted by the Informing Science Institute. Permission to make digital or paper copy of part or all of these works for personal or classroom use is granted without fee provided that the copies are not made or distributed for profit or commercial advantage AND that copies 1) bear this notice in full and 2) give the full citation on the first page. It is permissible to abstract these works so long as credit is given. To copy in all other cases or to republish or to post on a server or to redistribute to lists requires specific permission and payment of a fee. Contact 0HPublisher@InformingScience.org to request redistribution permission. ject.

Agile approaches are known to increase the speed of development using short development cycles called sprints, typically one week, after which a tangible part of a system is delivered. This approach is different from a plan-based project methodology using a traditional waterfall development approach where there is considerable upfront planning, 
analysis and design prior to the build and delivery phases. There is considerable debate in the literature currently regarding the merits and demerits of the differing approaches.

At the University of Cape Town, the Information Systems major utilizes both approaches. In the $3^{\text {rd }}$ year, having been taught the traditional systems development methodologies and project management techniques, student groups build a system using the waterfall approach. In the $4^{\text {th }}$ year, students are taught SCRUM and use this iterative approach in teams to build a system.

Whilst the two approaches have very different characteristics, both seem to produce successful outcomes in the university setting.

This initial research investigates three behavioral issues which may affect team member productivity in both a traditional waterfall project and in a Scrum project: the management of stress, the use of slack and the student syndrome. These will be described in detail in the following sections. Based on the derived research questions, subsequent research will attempt to measure how these 3 issues affect team performance and project success.

\section{Productivity Issues in Student Projects}

Scott and Pollock (2006) researched team performance in undergraduate student projects. They claimed that teamwork, the project experience and the quality of the final software product contributed to team performance. These three factors are enhanced, they claim, by allowing the team to be self-selected.

As students learn about different systems development and project management methodologies (the hard factors) they also learn about behavioral issues (the soft factors). The latter can be through formal courses or through informal experience in the various projects.

This research is focused on behavioral issues which may have different consequences depending on the systems development approach used. The student syndrome is a natural phenomenon describing when real work starts to take place. Stress increases when deadlines are close or when the work effort continues over a long period. Slack is a rich period of time allowing reflection and innovation?

These three phenomena will be described in further detail before discussing them in the context of student development projects.

\section{Student Syndrome}

According to Lechler, Ronen \& Stohr (2005), the two behavioral issues addressed by the Critical Chain Project Management Theory are the student syndrome and Parkinson's Law. The latter addresses the issue whereby humans tend not to complete work ahead of schedule even if they are able to. The student syndrome applies when humans start tasks as late as possible and waste safety margins, thereby putting themselves under pressure and stress. The Critical Chain approach goes a stage further and avoids calendar-based milestones in an attempt to prevent "self-fulfilling prophesies" occurring. The approach also claims that the fewer the number of concurrent tasks a person works on the better. Robinson and Richards (2009) argue that despite building in safety and time contingencies into project estimates, procrastination, or student syndrome, remains a major problem. They claim that many tasks in the workplace are only executed when the level of urgency is high enough to ensure effort is put into the task. When this happens it is often too late to cater for unexpected issues that may arise as all the contingency time has been squandered. 


\section{Stress}

Stress itself is not necessarily bad. "The term stress can be considered neutral with the words distress and eustress used for designating bad and good effects" (French, Kast \& Rosenzweig, 1985, p. 16). They proposed a model that defined an optimum range of stress in terms of its effect on performance. They claimed that stress levels that exceed an optimum level result in decreased performance and eventual burnout, whereas stress levels that were below a minimum level result in decreased performance.

Stress can associated with the student syndrome as, where there is minimal stress in a work situation, there may be a corresponding increase in student syndrome. Where stress levels are high, the student syndrome might be reduced.

Stanton (2006) found that high stress levels negatively impacted on the health and well-being of the individual. Individuals experiencing high levels of stress suffer psychological symptoms such as job dissatisfaction, low self esteem, reduced motivation, anxiety, depression and decreased organizational commitment (Kaluzniacky, 1998; Sun \& Doong, 1999). These symptoms inhibit the affected individual from learning and developing new skills and knowledge. This situation is made worse when individuals experience burnout (due to chronic stress) as they could suffer high levels of emotional exhaustion, depression, listlessness and sleeping problems (Chan \& Chau, 2001).

Organizational costs related to stress are high. Impacts due to stress include poor employee performance, reduced productivity, increased absenteeism, increased turnover, failed organization change initiatives, lost working days and retraining of replacement staff (Clarke \& Cooper, 2004). The high turnover in the IT industry is often attributed to the highly stressful workplace environment that is encountered (Teo \& Lim, 1999). Hong and Kim (2002) found that $75 \%$ of Enterprise Resource Planning (ERP) projects were judged to be unsuccessful due to the high stress environment.

Recent research findings in South Africa concluded that IT project managers experienced very high levels of stress. Unlike other studies, these project managers coped with stress using predominantly mal-adaptive strategies like venting, denial, self-blame and self-distraction (Smith, de Passos, \& Isaacs, 2010).

In financial terms, the annual economic cost of stress in 15 European countries in 2007 was estimated at $€ 20$ billion, and more than $\$ 300$ billion (together with 80 million work days lost every year) in the USA (Brun \& Milczarek, 2007).

\section{Slack}

McDonald (2003) identified organizational slack as a negative term traditionally relating to inefficiency and uncommitted resources. In his case-study research on slack, he concluded that respondents did not discuss money but were strongly focused on wanting more time.

In his popular book entitled Slack, DeMarco (2001) argued that contemporary organizations tend to focus on staff being busy (fully occupied and 100\% scheduled) which he argued leads to organizational inertia, high staff turnover and general inefficiency. He proposed that flattening the organization, a current management trend, has created a middle management layer that is focused on "busyness" and not on their main role which, he argues, is "reinvention". He concluded that making everybody fully occupied is a short-term strategy which will negatively affect longerterm change and reinvention. Reinvention, he argues, requires slack. In an interview DeMarco states "If you haven't a clue how to motivate, encourage innovation, form rich communities of practice, help teams gel, or hire people who add immeasurably to your organization without disrupting its fragile chemistry, then you tend to talk about running a tight ship" (Myers, 2001). He 
defined a tight ship having little slack and therefore not allowing adequate innovation in a knowledge organization. Innovation is required in a systems development project.

Boule, Garrett, and Karabus (2001) investigated team effectiveness in project-based organizations (PBO). They concluded that the move to a PBO tended to encourage the use of short-lived teams where resource usage is optimized and scarce skills over-utilized. This approach, they argued, reduced slack time and created lots of hidden inefficiencies.

\section{Agile Methods and SCRUM}

A plan-based development approach consists of a considerable amount of planning and paperwork in the early stages of the project (use of the PMBoK, PRINCE2 and the traditional waterfall development approach fit into this category). This approach produces an entire software product at the end. Deadlines and due dates are driven by the project plan (Harris, Collins, \& Hevner, 2009) and these dates tend to motivate and increase productivity. In the early stages there may be evidence of slack available for innovative thinking and the student syndrome will be present. Nearer the end of the development process, time will be critical and stress levels will become extremely high.

Agile methods, on the other hand, follow short development iterations with frequent software releases. Harris, Hevner, and Collins (2009) propose that when using agile methods, short continuous deadlines will increase stress levels. However, these iterations can also lead to increased motivation of team members. In SCRUM, the continuous short sprints can lead to stress but each sprint ends with a retrospective (a powerful technique and one that supports innovation).

At the University of Cape Town, the Department of Information Systems uses both approaches in different years. In the $3^{\text {rd }}$ year, self-selected student teams (of 5) build a system using a waterfall development approach and traditional project management techniques. In the $4^{\text {th }}$ year, student teams use the SCRUM approach in their systems development project and are strongly encouraged to complete Retrospectives after each sprint.

\section{Research Design}

The research questions derived from the literature survey are:

- Do the stress levels of project team members differ when using the SCRUM approach and traditional project management approaches?

- Are the stress coping mechanisms maladaptive or adaptive in the two approaches?

- Is the student syndrome reduced when using the SCRUM approach?

- Is the Retrospective technique used in SCRUM the equivalent of slack time and used for innovation in the development process?

The intention is to identify a suitable student project which can be allocated to a $3^{\text {rd }}$ year team who will be using a traditional development approach and the same project will also be allocated to a $4^{\text {th }}$ year team who will use SCRUM. The author will investigate the effects of stress, student syndrome and slack over the duration of the two projects and determine how these affect productivity and the final project outcome. 


\section{Conclusion}

Assessing productivity in systems development project teams is an ongoing research theme. This research-in-progress has identified three behavioral issues that may affect systems development project productivity and project outcomes. A research review has identified stress, slack and the student syndrome as having different productivity effects on a plan-based project as opposed to a SCRUM-based project. Four research questions were developed and will be analyzed using empirical evidence from actual projects to understand how these 3 behavioral aspects interact and their overall impact on the productivity of IS project teams. There is considerable scope for further research into the impact of these behavioral issues on Agile development methodologies.

\section{References}

Boulle, A., Garrett, M. \& Karabus, M. (2001). Information systems team effectiveness within project-based organizations. Unpublished Empirical Research Report, Department of Information systems, University of Cape Town.

Brun, E., \& Milczarek, M. (2007). Expert forecast on emerging psychosocial risks related to occupational safety and health. European Agency for Safety and Health at Work.

Chan, I., \& Chau, P. Y. (2001). A proposed conceptual model for studying job stress in IT professionals. Americas Conference on Information Systems, pp. 1475-1478. Boston.

Clarke, S., \& Cooper, C. L. (2004). Managing the risk of workplace stress. London: Routledge.

DeMarco, T. (2001). SLACK: Getting past burnout, busywork, and the myth of total efficiency. New York: Broadway Books.

French, W., Kast, F., \& Rosenzweig, J. (1985). Understanding human behavior in organizations. New York, NY: Harper \& Row.

Harris, M. L., Collins, R. W., \& Hevner, A. R. (2009). Agile methods: Fast-paced, but how fast? Proceedings of Fifteenth Americas Conference on Information Systems, San Francisco, California, August $6^{\text {th }}$ $9^{\text {th }}$.

Harris, M. L., Hevner, A. R. \& Collins, R. W. (2009). Controls in flexible software development. Communications of the AIS, 24(43).

Hong, K.-K., \& Kim, Y.-G. (2002). The critical success factors for ERP implementation: An organizational fit perspective. Information \& Management, 40(1), 25-40.

Kaluzniacky, E. (1998). An assessment of stress factors among information systems professionals in Manitoba. SIGCPR: ACM Special Interest Group on Computer Personnel Research, March 26-28, pp. 254-257. Boston: ACM.

Lechler, T. G., Ronen, B. \& Stohr, E. A. (2005). Critical chain: A new project management paradigm or old wine in new bottles. Engineering Management Journal, 17(4), 45-58.

McDonald, S. (2003). Innovation, organisational learning and models of slack. $5^{\text {th }}$ International Conference on Organisational Learning and Knowledge, Lancaster University, $30^{\text {th }}$ May- $2^{\text {nd }}$ June.

Myers, W. (2001). Developers need some slack. IEEE Software, July/August, 90-92.

Robinson, H., \& Richards, R. (2009). An introduction to critical change project management. AACE International Transactions, PS.S03.1 to PS.S03-11.

Scott, E., \& Pollock, M. (2006). Effectiveness of self-selected teams: A systems development project experience. Issues in Informing Science and Information Technology, 3, 601-617. Retrieved from http://informingscience.org/proceedings/InSITE2006/IISITScot217.pdf

Smith, D., de Passos, J. \& Isaacs, R. (2010). How IT project managers cope with stress. Proceedings of the ACM SIGMIS CPR Conference, 20-22 May, Vancouver. 
Stanton, J. (2006). Hazardous work - is the risk obvious? Manufacturers' Monthly, 18-19.

Sun, S.-Y., \& Doong, H. S. (1999). A study of the job and its effect of the information system professional in Taiwan. Americas Conference on Information Systems, August 13-15, Milwaukee: ACM.

Teo, V. K., \& Lim, T. S. (1999). Occupational stress and IT personnel in Singapore: Factorial dimensions and differential effects. International Journal of Information Management, 19(4), 277-291.

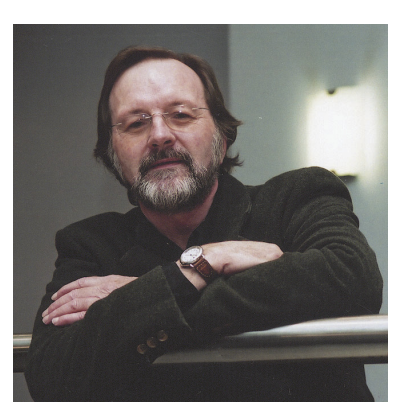

\section{Biography}

Derek Smith is currently Professor of Information Systems at the University of Cape Town. Prior to becoming an academic, he worked as an IT manager for large organizations in various countries. He is cofounder of a successful private training institution in South Africa. Derek is a frequent speaker at international and local conferences and has published a wide range of academic books, articles and papers focusing on project management and people management. He is a certified Project Management Professional (PMP) and an active member of the Project Management Institute (PMI) and the local Cape Town chapter. 